\title{
Validation of the Quality of Life Multiple Myeloma Module Questionnaire (QLQ-MY20) in Portuguese myeloma patients
}

\author{
M. Graça Pereira ${ }^{1,2}$ (D) | Gabriela Ferreira ${ }^{1,2}$ (D) | Marta Pereira ${ }^{1,2}$ (D) | Sara Faria ${ }^{1}$ \\ Rosário Bacalhau $^{3}$ (D) | Sara Monteiro ${ }^{4,5}$ | | Bruna Fernandes ${ }^{4}$ | Margarida Vilaça ${ }^{2}$ (D)
}

\author{
${ }^{1}$ School of Psychology, University of Minho, \\ Braga, Portugal \\ ${ }^{2}$ Psychology Research Center \\ (CIPsi), University of Minho, Braga, Portugal \\ ${ }^{3}$ Portuguese Institute of Oncology Francisco \\ Gentil, Lisboa, Portugal \\ ${ }^{4}$ Department of Education and \\ Psychology, University of Aveiro, Aveiro, \\ Portugal \\ ${ }^{5}$ Center for Health Technology and Services \\ Research (CINTESIS), University of Porto, \\ Porto, Portugal

\section{Correspondence} \\ M. Graça Pereira, School of Psychology, \\ University of Minho, Campus de Gualtar, \\ 4710-057 Braga, Portugal. \\ Email: gracep@psi.uminho.pt \\ Funding information \\ This study was supported by a grant from \\ the Portuguese Associations of Portuguese \\ Association against Leukemia and the \\ Portuguese Association of Leukemias and \\ Lymphomas.
}

\begin{abstract}
Objective: The aim of this study was the validation of the European Organization for Research and Treatment of Cancer's Multiple Myeloma Module (QLQ-MY20) in Portuguese myeloma patients.

Methods: A total of 213 Portuguese patients diagnosed with multiple myeloma participated in this study and were assessed with the European Organization for Research and Treatment of Cancer's (EORTC) Questionnaire C30 (QLQ-C30), the EORTC Multiple Myeloma Module (QLQ-MY20), the Hospital Anxiety and Depression Scale (HADS) and the Satisfaction with Social Support Scale (SSSS).

Results: The validated version includes 17 items presenting good global adjustment and good internal consistency. Overall, the Portuguese validation maintains the original model with the exception of three items that were excluded. The instrument also showed good reliability and good convergent and divergent validity.

Conclusion: The Portuguese version of the EORTC Multiple Myeloma Module questionnaire seems to be a valid instrument for myeloma patients to help monitor interventions in this population focused on the promotion of quality of life.
\end{abstract}

\section{KEYWORDS}

myeloma, psychological morbidity, QLQ-MY20, quality of life, social support

\section{1 | INTRODUCTION}

Multiple myeloma (MM) is the second most prevalent haematological cancer (Gozzetti, Candi, Papini, \& Bocchia, 2014; Lamers et al., 2013), with the genesis on plasma cells in the bone marrow, resulting in excessive production of monoclonal paraprotein by means of malignant plasma cells. This disease is incurable (Smith, Howell, Patmore, Jack, \& Roman, 2011), with a 5-year survival rate of $50 \%$ between 2007 and 2013 in the United States (American Cancer Society [ACS], 2017).

Patients with MM have higher levels of symptoms as well as a poorer quality of life (QoL), when compared with patients with other haematological cancers (Johnsen, Tholstrup, Petersen, Pedersen, \& Groenvold, 2009). This fact may be related to bone pain, pathological fractures and recurrent infections due to impaired immune function (Johnsen et al., 2009). According to Maes and Delforge (2015), QoL in patients with $\mathrm{MM}$ is influenced by symptoms associated with the disease, toxicity related to the treatment and response to treatment.

Likewise, the recommended treatment with transplantation of hematopoietic stem cells (HSCT) is very aggressive in these patients, who often report physical and emotional distress and a decrease in their QoL within the first 3 years after transplantation (Sutherland et al., 1997). The physical consequences of this treatment include symptomatic array, such as fever, fatigue, nausea, vomiting, mouth sores, infections and transplant rejection (Wells, Booth-Jones, \& Jacobsen, 2009). This fact is corroborated by other studies that have suggested that patients with MM showed weaknesses in their QoL, particularly in terms of global QoL, physical, role, cognitive and 
social functioning, as well as pain, breathlessness, loss of appetite, memory problems, insomnia, constipation and financial difficulties (Molassiotis, Wilson, Blair, Howe, \& Cavet, 2011b; Mols et al., 2012).

In addition to physical symptoms, psychological and social problems have also significant implications on patients' QoL (Frodin, Borjeson, Lyth, \& Lotfi, 2010; Molassiotis, Wilson, Blair, Howe, \& Cavet, 2011a). In fact, patients with MM have a great psychological vulnerability (Broers, Kaptein, Cessie, Fibbe, \& Hengeveld, 2000), due to the physical, social and psychological stressors that this disease triggers. Mosher, Redd, Rini, Burkhalter, and Duhamel (2009) found that survivor patients undergoing HSCT experience significant and persistent symptoms of anxiety and depression, fatigue, sexual dysfunction and concerns about fertility, having been exposed to a myriad of stressors that exacerbate their psychological distress, such as prolonged hospitalisation, invasive medical procedures, isolation, change in appearance, fear that the transplant does not result and fear of death (Lee et al., 2005).

Regarding the moment of transplantation, which implies an invasive and stress-inducing surgery, Sherman, Simonton, Latif, Plante, and Anaissie (2009) found that patients with MM, prior to transplantation, showed several deficits, namely in physical and functional well-being, fatigue and pain, as well as significant clinical levels of anxiety (39.4\%), depression (40.4\%) and cancer-related anxiety (37.0\%). After transplantation, there was a worsening of the concerns related to the transplant, depression and life satisfaction, however, there was an improvement in terms of pain and social functioning. Thus, a significant percentage of patients with MM report psychosocial and physical functioning compromise and about a third, clinically elevated levels of distress, anxiety and depression (Sherman, Simonton, Latif, Spohn, \& Tricot, 2004). In fact, anxiety was negatively associated with a deficit in terms of QoL in cancer patients, including patients with MM (Stark et al., 2002).

Once the treatment for MM occurs mainly in an outpatient setting, patients have to endure the most physical and emotional care at home (Molassiotis et al., 2011b). This fact contributes to the patients' burden, in terms of time spent in managing symptoms, as well as the financial outlay that this situation imposes. The significant physical weakness and the deteriorating condition have a big impact on patients, requiring resources to deal with these demands, such as social support.

Social support is a resource that directly affects health, buffering the effect of stress due to experienced adversities (Wenzel et al., 2002). Frick, Rieg-Appleson, Tyroller, and Bumeder (2006) emphasise that social support is essential for patients undergoing HSCT, not only during hospitalisation phase, but also for the post-discharge period, being positively associated with the level of survival (Colón, Callies, Popkin, \& McGlave, 1991; Frick, Motzke, Fischer, Busch, \& Bumeder, 2005; Rodrigue, Pearman, \& Moreb, 1999) and with better QoL (Frick et al., 2006). Particularly, patients receiving social support from spouses reported better QoL than patients who identified others as the main source of social support. Also, patients with MM that reported lower social support before HSCT showed higher levels of anxiety and depression (Wells et al., 2009). Therefore, family support and social relationships contribute to higher levels of QoL, assuming an important buffer role regarding the impact of stress (Molassiotis, Akkew, \& Boughton, 1997).

Taking into consideration the negative influence of symptoms associated with the disease, toxicity related to the treatment and response to treatment on QoL of MM patients, it becomes important to have validated measures to assess QoL related to the specific symptoms triggered by this type of cancer. Therefore, this study aims to validate the Quality of Life Multiple Myeloma Module Questionnaire-QLQ-MY20(Cocks et al., 2007), in a Portuguese sample of patients with MM.

\section{2 | METHODS}

\section{1 | Participants}

The sample included 213 patients with MM attending outpatient medical oncology and clinical haematology appointments at five hospitals from the north and centre of Portugal. The inclusion criteria comprised the following: (a) diagnosis of $\mathrm{MM}$; (b) being under treatment at the moment of assessment; (c) literate; (d) age equal or greater than 18 years; and (e) no cognitive deficit as assessed by the Mini-Mental State Examination.

\section{$2.2 \mid$ Measures}

European Organization for Research and Treatment of Cancer (EORC)Quality of Life Multiple Myeloma Module Questionnaire (QLQ-MY20; Cocks et al., 2007; Pereira et al., unpublished results). The QLQMY2O is a multidimensional specific questionnaire designed to assess QoL in MM cancer patients. It includes 20 items describing two symptom scales: Disease Symptoms (DS; 6 items) and Side Effects of Treatment (SE; 10 items); one functional scale: Future Perspective (FP; 3 items) and one single item regarding Body Image (BI), all items scored on a 4-point Likert scale (1 = "not at all," 2 = "a little," 3 = "quite a bit," 4 = "very much"). In the symptom scales, higher scores denote more symptoms, while for FP and $\mathrm{BI}$, high scores indicate better perceptions of the future and body image. The original QLQ-MY version (Cocks et al., 2007) presented good internal consistency (Cronbach's alpha) for all scales: $\mathrm{DS}=0.76, \mathrm{SE}=0.82$ and $\mathrm{FP}=0.79$.

European Organization for Research and Treatment of Cancer (EORC)-Quality of Life Questionnaire Core-30 (QLQ-C30; Aaronson et al., 1993; Portuguese Version by Pais-Ribeiro, Pinto, \& Santos, 2008). The original QLQ-C30 consists of 30 items to evaluate the QoL of patients with cancer. The questionnaire assesses five functional subscales (Physical, Role, Emotional, Social and Cognitive Functioning; 15 items), nine symptom subscales/items (Fatigue, Pain, Nausea and Vomiting, Dyspnoea, Sleep, Appetite Loss, Constipation, Diarrhea and Financial Difficulties; 13 items) and a Global Health Status (2 items). In addition to the subscales' results, a summary score can also be calculated by the sum of 13 of the 15 subscales (Financial Difficulties and Global Health Status' items/subscale are not included). Patients were asked to score all items on a 4-point Likert scale ranging from 1 ("not at all") to 4 ("very much"), except for the global health status dimension that presents a linear analogue scale alternating from 1 ("very poor") to 
TAB LE 1 Sample's socio-demographic and clinical characterisation

\begin{tabular}{|c|c|}
\hline Patients ( $N=213$ ) & $n(\%) / M \pm S D$ \\
\hline \multicolumn{2}{|l|}{ Gender } \\
\hline Women & $107(50.2)$ \\
\hline Men & $106(49.8)$ \\
\hline Age (years) & $67.34 \pm 10.56$ \\
\hline \multicolumn{2}{|l|}{ Age group } \\
\hline$<60$ & $41(19.2)$ \\
\hline $60-69$ & $77(36.2)$ \\
\hline$>70$ & $95(44.6)$ \\
\hline \multicolumn{2}{|l|}{ Education } \\
\hline$\leq$ Basic education & $149(64.8)$ \\
\hline$\leq$ Secondary education & $31(14.5)$ \\
\hline$\leq$ University degree & $35(16.4)$ \\
\hline \multicolumn{2}{|l|}{ Professional status } \\
\hline Employed & $25(11.7)$ \\
\hline Unemployed & $22(10.4)$ \\
\hline Retired & $166(77.9)$ \\
\hline Disease duration (months) & $45.99 \pm 42.78$ \\
\hline \multicolumn{2}{|l|}{ Cancer stage } \\
\hline 1 & $77(36.2)$ \\
\hline II & $59(27.7)$ \\
\hline III & $53(24.9)$ \\
\hline \multicolumn{2}{|l|}{ Myeloma type } \\
\hline $\lg A / L$ & $29(13.6)$ \\
\hline $\lg A / K$ & $41(19.2)$ \\
\hline $\operatorname{lgG} / \mathrm{K}$ & $81(38.0)$ \\
\hline $\operatorname{lgG} / \mathrm{L}$ & $32(15.0)$ \\
\hline Other & $30(14.1)$ \\
\hline \multicolumn{2}{|l|}{ Treatments received } \\
\hline Chemotherapy & $63(29.6)$ \\
\hline Chemotherapy and transplant & $52(24.4)$ \\
\hline Chemotherapy and bisphosphonates & $22(10.3)$ \\
\hline $\begin{array}{l}\text { Chemotherapy, transplant and } \\
\text { bisphosphonates }\end{array}$ & $15(7.0)$ \\
\hline Others & $56(26.2)$ \\
\hline \multicolumn{2}{|l|}{ Current treatment } \\
\hline Chemotherapy & $83(39.0)$ \\
\hline Maintenance therapy & $81(38.0)$ \\
\hline Other & $44(20.6)$ \\
\hline
\end{tabular}

7 ("excellent"). Only the summary score was considered in the current study and higher results reflected better QoL. Cronbach's alpha for the global scale was 0.87 .

Hospital Anxiety and Depression Scale (HADS; Zigmond \& Snaith, 1983; Portuguese Version by Pais-Ribeiro et al., 2007). A self-report brief questionnaire (14 items) designed to evaluate psychological morbidity in community and clinical populations by the assessment of anxiety and depression symptoms. Both subscales, Anxiety and Depression are composed of seven items each, evaluated on a 4point Likert scale. The higher the scores, the more serious the anxiety and depression. The Portuguese version presented Cronbach's alphas of 0.76 for the subscale Anxiety and 0.82 for the subscale Depression. In the present study, the total score was used as an indicator of psychological morbidity/emotional distress. Alpha's coefficient for the total HADS was 0.81.

Satisfaction with Social Support Scale (SSSS; Portuguese version by Pais-Ribeiro, 1999). Satisfaction with Social Support Scale comprises 15 items that measure satisfaction with social support, including the following subscales: Satisfaction with Friends (SFrie; 5 items), Intimacy (IN; 4 items), Satisfaction with Family (SF; 3 items) and Social Activities (SA; 3 items). In addition to the subscales, a full score can be obtained through the sum of the 15 items. Higher results indicate a greater satisfaction with social support. The original version showed Cronbach's alphas of 0.85 for the total score and 0.83 (SFrie), 0.74 (IN and SF) and 0.64 (SA) for the subscales. In this study, only the total scale was used with Cronbach's alpha of 0.89 .

\section{3 | Procedure}

This study used a cross-sectional design and was approved by the Ethics Committees of the hospitals where data collection took place, following all principles outlined in the Declaration of Helsinki. Patients were identified and invited to participate in the study by their physicians. Data collection took place on the day of patients' medical appointment or treatment. Patients were informed about the aims of the study, confidentiality of the data and voluntary participation. All participants signed an informed consent.

\subsection{Data analysis}

All statistical analyses were undertaken using the SPSS (SPSS Inc.) and AMOS (IBM Corp.) software programs, version 25. First, descriptive analyses were used (frequencies, percentages, means and standard deviations) to describe socio-demographic and clinical characteristics of participants. A confirmatory factor analysis (CFA) was performed using the LISREL model. The fit to the original QLQ-MY20 model was tested by computing Comparative Fit Index (CFI), TuckerLewis Index (TLI) and Root Mean Square Error of Approximation (RMSEA). For CFI and TLI were expected values above 0.90 if the fit was adequate (Hu \& Bentler, 1995), while for RMSEA a value under 0.08 was considered acceptable (Hair, Anderson, Tatham, \& Black, 1995). In addition to the goodness-of-fit indices, the overall fit of the model was evaluated through additional data such as reliability. Thus, the internal structure validity of the scales was assessed using Cronbach's alpha coefficients, with values over 0.70 being expected (Cronbach, 1951). To explore convergent and divergent validity, relationships between the dimensions of the QLQ-MY resulting version (DS, SE, BI, FP) and global scores of QLQ-C30, SSSS and HADS questionnaires were measured using Pearson's correlation coefficients. 
Social support was used to test convergent validity since there is a strong association with patients' QoL (Frick et al., 2006; Molassiotis et al., 1997). Similarly, psychological morbidity was included to test divergent validity, due to its negative impact on patients' QoL (Broers et al., 2000; Stark et al., 2002). Finally, the QLQ-MY's mean dimensions scores were compared considering patients qualitative (gender, age group, cancer stage and myeloma type) and quantitative (disease duration) variables that were expected to vary, using Student's $t$ test, One-way ANOVA and Pearson's correlation coefficient, respectively.

\section{3 | RESULTS}

\section{1 | Patient characteristics}

A total of 213 Portuguese patients diagnosed with MM (107 women and 106 men) participated in this study. The average age was 67.34 years $(S D=10.56)$ with the majority of participants aged 70 years or over (44.6\%). As such, most of the respondents were professionally inactive (retired) (77.9\%) and had basic education or less (64.8\%). Regarding the participants' clinical characterisation, on average, they were diagnosed with $\mathrm{MM}$ almost 4 years ago ( $M=45.99$ months;
$S D=42.78$ months), predominantly with lgG/K myeloma type (38.0\%) in stage I (36.2\%). Concerning treatment's aspects, the majority of patients were submitted to chemotherapy in the past $(29.6 \%)$ or were receiving chemotherapy in the assessment moment (39.0\%). Sample's characterisation is detailed in Table 1.

\section{2 | Construct validity}

Kaiser-Meyer-Olkin (KMO) sample adequacy test showed a value of $0.82(p<0.001)$ and Bartlett's test of sphericity reached statistical significance $\left(\chi^{2}=1858.26, p<0.001\right)$, supporting the feasibility of using factor analysis.

The CFA's results indicated that the data did not fit the original 4-factor structure, obtaining inadequate goodness-of-fit values: $\chi^{2} / d f=2.649, p<0.001, \mathrm{CFI}=0.855, \mathrm{TLI}=0.833$ and $\mathrm{RMSEA}=0.088$ (0.078-0.099). An inspection of the modification indices and the quality of the model leaded to the removal of items 7 ("Did you feel drowsy"), 11 ("Have you lost any hair?") and 12 ("Were you upset by the loss of your hair?") since they presented high correlations between errors variances and did not fit in the remaining two factors. As a result, the final re-specified model contained 17 items (see Figure 1), obtaining

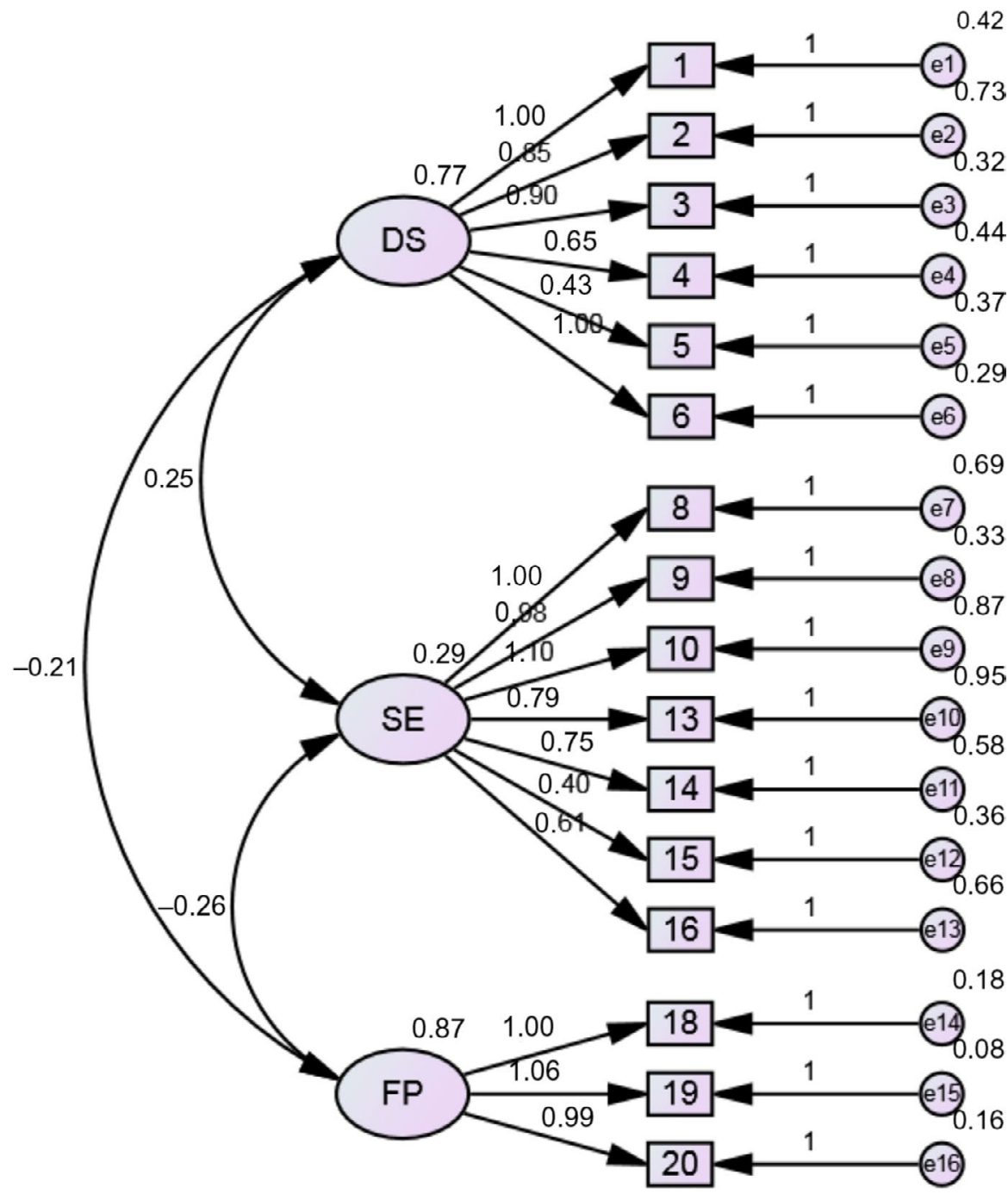

FIGURE 1 QLQ-MY re-specified model 
TAB LE 2 Statistical fit indices and Cronbach's alphas for the QLQ-MY Portuguese version

\begin{tabular}{|c|c|c|c|c|}
\hline Model & \multicolumn{2}{|c|}{ Domain } & Cronbach's alpha & Statistical fit indices \\
\hline \multirow{2}{*}{$\begin{array}{l}\text { Original QLQ-MY20 model (Cocks } \\
\text { et al., 2007) }\end{array}$} & SE: & $7 ; 8 ; 9 ; 10 ; 11 ; 12 ; 13 ; 14 ; 15 ; 16$ & 0.82 & \\
\hline & FP: & $18^{\mathrm{a}} ; 19^{\mathrm{a}} ; 20^{\mathrm{a}}$ & 0.79 & \\
\hline \multirow[t]{3}{*}{ Original model (20 items) } & DS: & $1 ; 2 ; 3 ; 4 ; 5 ; 6$ & 0.86 & \multirow{3}{*}{$\begin{array}{l}\text { Chi-square = } 394.68 \\
d f=149 \\
C F I=0.86 \\
\text { TLI }=0.83 \\
\text { RMSEA }=0.09(0.08-0.10)\end{array}$} \\
\hline & $\mathrm{BI}:$ & $17^{\mathrm{a}}$ & - & \\
\hline & FP: & $18^{\mathrm{a}} ; 19^{\mathrm{a}} ; 20^{\mathrm{a}}$ & 0.91 & \\
\hline \multirow[t]{3}{*}{ Re-specified model (17 items) } & DS: & $1 ; 2 ; 3 ; 4 ; 5 ; 6$ & 0.86 & \multirow{3}{*}{$\begin{array}{l}\text { Chi-square = } 192.03 \\
d f=101 \\
C F I=0.94 \\
T L I=0.93\end{array}$} \\
\hline & SE: & $8 ; 9 ; 10 ; 13 ; 14 ; 15 ; 16$ & 0.68 & \\
\hline & BI: & $17^{\mathrm{a}}$ & - & \\
\hline
\end{tabular}

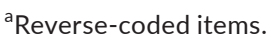

good global adjustment indices: $\chi^{2} / d f=1.901, p<0.001, C F I=0.940$, $\mathrm{TLI}=0.929$ and RMSEA $=0.065$ (0.051; 0.079). Table 2 summarises the goodness-of-fit statistics for the CFA analyses.

\section{3 | Reliability}

The Cronbach's alpha for internal consistency of the Portuguese QLQ-MY version (Table 2) suggests that the reliability of subscales was good (0.86-0.91), except for SE dimension that reported a satisfactory alpha coefficient (0.68), close to the recommended minimum value of 0.70 (DeVellis, 2003).

\subsection{Convergent validity}

The Portuguese QLQ-MY version's convergent validity was established taking into consideration the QoL in cancer (QLQ-C30) and the total social support scale (SSSS). As expected, QLQ-C30 and SSSS total scores correlated negatively with symptom scales (DS and $\mathrm{SE}$ ) and positively with functional scales/items (BI and FP) (Table 3). Questionnaire C30 obtained medium to large significant correlations with all QLQ-MY subscales (between 0.38 and -0.59), while SSSS presented lower but significant correlations (between -0.13 and 0.34) (Cohen, 1988), except for DS dimension that reported a nonsignificant small correlation $(r=-0.13, p=0.06)$.

\section{5 | Divergent validity}

Psychological poor (HADS) was used to assess QLQ-MY divergent validity. As shown in Table 3, the results showed positive associations between total psychological morbidity and symptom scales and negative associations with functional scales/items. Overall, the correlations' strength varied from small (DS: $r=0.25$ ) to medium (SE: $r=0.42$; $\mathrm{BI}: r=-0.31$ ) and large (FP: $r=-0.54$ ) (Cohen, 1988).
TABLE 3 Pearson's correlations between the QLQ-MY Portuguese version's subscales, Satisfaction with Social Support (SSSS) and Psychological Morbidity (HADS)

\begin{tabular}{|c|c|c|c|c|}
\hline & DS & SE & BI & FP \\
\hline \multicolumn{5}{|c|}{ QLQ-C30 } \\
\hline Total & $-0.589^{* * *}$ & $-0.547^{* * *}$ & $0.375^{* * *}$ & $0.493^{* * *}$ \\
\hline \multicolumn{5}{|l|}{ SSSS } \\
\hline Total & -0.129 & $-0.179^{* *}$ & $0.169^{*}$ & $0.335^{* * *}$ \\
\hline \multicolumn{5}{|l|}{ HADS } \\
\hline Total & $0.244^{* * *}$ & $0.422^{* * *}$ & $-0.312^{* * *}$ & $-0.536^{* * *}$ \\
\hline
\end{tabular}

\section{6 | Differences in QLQ-MY according to patients'} gender, age, cancer stage, myeloma type and disease duration

Analyses of the Portuguese version of the QLQ-MY scores accordingly to the sample's socio-demographic (gender and age group) and clinical (cancer stage, myeloma type and disease duration) characteristics are described in Table 4. Women reported significant higher scores for symptom scales and lower scores for functional scales/items, suggesting that female patients expressed more symptoms and worse perspectives regarding their future and body image, compared with male. Overall, no differences were found with regard to patients' age, except for the FP dimension since elder patients reported worse expectations about their future.

Regarding the patients' clinical conditions, no significant differences were found concerning the cancer stage and myeloma type. However, the disease duration revealed a significant positive weak correlation for SE dimension ( $r=0.15, p=0.032$ ), denoting that longer durations of disease were associated with perceptions of more side effects of treatment. 


\begin{tabular}{|c|c|c|c|c|}
\hline & DS & SE & BI & FP \\
\hline \multicolumn{5}{|l|}{ Gender } \\
\hline Women & $11.35 \pm 5.12$ & $12.95 \pm 3.77$ & $3.60 \pm 0.71$ & $7.81 \pm 3.02$ \\
\hline Men & $9.14 \pm 3.56$ & $11.89 \pm 3.69$ & $3.82 \pm 0.51$ & $9.05 \pm 2.71$ \\
\hline$p$ value & 0.000 & 0.038 & 0.009 & 0.002 \\
\hline \multicolumn{5}{|l|}{ Age group } \\
\hline$<60$ & $9.00 \pm 3.76$ & $11.32 \pm 3.03$ & $3.66 \pm 0.73$ & $9.29 \pm 2.50$ \\
\hline $60-69$ & $10.34 \pm 4.30$ & $12.70 \pm 3.67$ & $3.66 \pm 0.74$ & $8.94 \pm 2.78$ \\
\hline$>70$ & $10.72 \pm 4.97$ & $12.67 \pm 4.05$ & $3.77 \pm 0.47$ & $7.64 \pm 3.04$ \\
\hline$p$ value & 0.126 & 0.111 & 0.466 & 0.001 \\
\hline \multicolumn{5}{|c|}{ Cancer stage } \\
\hline 1 & $10.04 \pm 4.42$ & $11.86 \pm 3.55$ & $3.74 \pm 0.55$ & $8.94 \pm 2.71$ \\
\hline II & $11.19 \pm 5.32$ & $12.47 \pm 4.10$ & $3.59 \pm 0.72$ & $7.98 \pm 2.95$ \\
\hline III & $10.25 \pm 4.33$ & $12.72 \pm 3.53$ & $3.74 \pm 0.68$ & $7.89 \pm 3.18$ \\
\hline$p$ value & 0.344 & 0.393 & 0.359 & 0.072 \\
\hline \multicolumn{5}{|c|}{ Myeloma type } \\
\hline $\operatorname{IgA} / \mathrm{L}$ & $9.93 \pm 4.71$ & $12.34 \pm 3.00$ & $3.76 \pm 0.64$ & $9.21 \pm 2.02$ \\
\hline $\operatorname{lgA} / \mathrm{K}$ & $10.56 \pm 5.14$ & $12.46 \pm 4.15$ & $3.76 \pm 0.62$ & $8.07 \pm 3.17$ \\
\hline $\operatorname{lgG} / \mathrm{K}$ & $10.42 \pm 4.31$ & $12.04 \pm 3.03$ & $3.69 \pm 0.68$ & $8.51 \pm 2.88$ \\
\hline $\operatorname{lgG} / \mathrm{L}$ & $10.22 \pm 4.53$ & $12.78 \pm 4.68$ & $3.75 \pm 0.51$ & $8.59 \pm 3.18$ \\
\hline Other & $9.70 \pm 4.48$ & $13.10 \pm 4.60$ & $3.60 \pm 0.62$ & $7.77 \pm 3.13$ \\
\hline$p$ value & 0.928 & 0.715 & 0.828 & 0.363 \\
\hline \multicolumn{5}{|c|}{ Disease duration } \\
\hline$R$ & -0.41 & 0.147 & 0.049 & 0.069 \\
\hline$p$ value & 0.548 & 0.032 & 0.476 & 0.317 \\
\hline
\end{tabular}

TABLE 4 Comparisons

(mean \pm standard deviation) and correlations ( $r$ ) between QLQ-MY results and patients' characteristics

\section{4 | DISCUSSION}

This study examined the psychometric proprieties of the Portuguese version of the QLQ-MY questionnaire considering the structural, internal consistency, convergent, divergent and discriminant validity. Results suggest that the resulting 17-items version is a valid and reliable tool to assess QoL in patients with myeloma cancer and, therefore, allowing health professionals to improve personalised care plans for these patients.

The original QLQ-MY20 validation study (Cocks et al., 2007) was based on a sample of 240 international (European and American) myeloma patients, mostly men (58.8\%), on average with 62.3 years old. Similarly, in the current study, a sample of 213 Portuguese MM patients was used, women and men equally distributed, on average with 67.3 years old. Also, in both samples the majority of patients had/were having chemotherapy as treatment. The CFA's results indicated that the original 4-factor model was feasible and fitted the Portuguese data well, after excluding three items from the original SE dimension. Specifically, questions that refer to sleepiness' sensation and hair loss (items 7, 11 and 12) were eliminated from the Portuguese version, which may make sense if we consider that the great majority of the participants were elderly patients, coping with myeloma cancer for 4 years in average. Furthermore, the majority of respondents answered that they did not have hair loss (69\%) or had a slight hair loss (15\%), compromising the answers to items 11 and 12. Regarding internal consistency, the obtained Cronbach's coefficient values for scales were higher than the original alpha coefficients, except for SE dimension that presented a lower value (Table 2).

The convergent validity showed that the QLQ-C30 and SSSS total scores correlated negatively with symptom scales (DS and SE) and positively with functional scales/items (BI and FP). In fact, patients with $\mathrm{MM}$ with a high level of symptoms present worse QoL when compared with patients with other haematological cancers (Maes \& Delforge, 2015), particularly bone pain, pathological fractures and recurrent infections due to impaired immune function (Johnsen et al., 2009; Lamers et al., 2013). The deterioration in the QoL of MM patients occurs particularly in terms of global QoL, physical, role, cognitive and social functioning, as well as pain, breathlessness, loss of appetite, memory problems, insomnia, constipation and financial difficulties (Molassiotis et al., 2011b; Mols et al., 2012). Family support and social relationships contribute to higher levels of QoL, assuming an important buffer over the impact of stress (Molassiotis et al., 1997). A study with patients with MM showed that social relationships were considered more important for QoL than aspects related to their health (Dürner, Reinecker, \& Csef, 2013). In the QoL's model of Wilson and Cleary (1995) adapted to patients with MM, social support is crucial, impacting directly on QoL. In addition, the symptoms only impact QoL when patient's functionality, emotional 
state and support sources are also affected (Osborne et al., 2014). However, no significant results were found between the symptom DS subscale and social support. This result may be explained by the fact that most of the participants our sample is over 70 years old, usually focused on solving instrumental problems and identifying more adaptive forms of cancer treatment compared to younger ones (Blanchard-Fields, Mienaltowski, \& Seay, 2007). Also, older patients may have lived a satisfactory life and enjoyed family support and good financial status, reflecting a greater ability to cope with cancer than younger patients (Cordella \& Poiani, 2014) and this adaptation, in turn, may be associated with less disease symptoms.

The divergent validity showed a positive correlation between total HADS and symptom scales and negative correlations with functional scales/items. A significant percentage of MM patients report psychosocial and physical functioning impairment, as well as high levels of anxiety and depression (Sherman et al., 2004). Another study found anxiety negatively associated with QoL in cancer patients, including patients with MM (Stark et al., 2002). Patients with higher anxiety and depressive symptoms have a lower social functioning, more sense of disability, and therefore, a greater overall functional impairment when compared to patients without these conditions (Katon, 2003).

In terms of the differences regarding the socio-demographic and clinical characteristics, women reported higher scores for symptom scales and lower scores for functional scales/items, suggesting that female patients expressed more symptoms and worse perspectives regarding their future and body image, compared with male patients. According to the literature, maintaining the social role and remaining active is crucial for patients' QoL (Mortensen \& Salomo, 2016). Culturally, women have a more active role in the family. For this reason, when faced with the latter obligations, women may feel more limitations, valuing more the symptoms when compared to men, what may trigger a more negative perception of the future. In fact, studies have shown that symptom distress is closely related to contexts that challenge patients' relationships and activities (Boland et al., 2013; Potrata, Cavet, Blair, Howe, \& Molassiotis, 2011). Regarding body image, and as corroborated by the literature (Ålgars et al., 2009; Krok, Baker, \& McMillan, 2013; Woertman \& van den Brink, 2012), the results showed a more negative perception of their body image compared to men. Evolutionary and sociocultural perspectives show that gender is an important determinant of body satisfaction (Ålgars et al., 2009; Woertman \& van den Brink, 2012), with women reporting higher levels of body dissatisfaction than men, as a result of the rigidity of cultural beauty ideologies (Striegel-Moore \& Franko, 2004). In this sense, due to the gender social construction, any change in body image will have more impact and will be more sensitive for women than men. Elder patients also reported worse expectations about their future. Older people have a higher risk of comorbidities due to biological ageing, which is associated with organ dysfunction, less resilience to physiological stress and reduced functional status (Fried, Ferrucci, Darer, Williamson, \& Anderson, 2004), hospitalisations, dependence and reduction of life expectancy (Wedding, Honecker, Bokemeyer, Pientka, \& Höffken, 2007), explaining the worst future perspectives.
No significant differences were found concerning the cancer stage and myeloma type, on QoL. Regarding disease stage, the absence of significant differences may be due to the fact that patients with MM present a high symptom burden and low QoL at both the more advanced and early stages (Ramsenthaler et al., 2016). Regarding myeloma type, no differences were reported on QoL probably due to the predominance, in the sample, of type $\lg \mathrm{G} / \mathrm{K}$ (38\%) compared to the other types.

However, the disease duration revealed a positive correlation with the SE dimension, denoting that longer duration was associated with the perceptions of more treatment side effects. Longer disease duration may imply greater toxicity due to long and recurrent antineoplastic treatments, which entail long-term side effects (Osborne et al., 2014). These effects, together with the patient's age range (secondary comorbidities), may result in a higher prescription of strong analgesic/opioids, which in turn may also be responsible for long-term side effects (Sloot et al., 2014).

The previous findings indicate that the 17-item Portuguese version of QLQ-MY represents a useful, practical and valid tool to assess QoL in Portuguese myeloma patients. Overall, the Portuguese version seems to be representative of the original version, and although the SE subscale contains less three items, it provides data that are comparable with those found in the original English version.

\section{5 | LIMITATIONS}

There are some limitations in this study that need to be acknowledged such as the specificities of the sample that include elderly patients coping with cancer disease for approximately 4 years and reporting no alopecia. Future studies should validate the QLQ-MY Portuguese version in samples with patients suffering from hair loss, diagnosed with myeloma cancer for a shorter period of time with a fair distribution of subtypes of $\mathrm{MM}$ and cancer stages. Convergent validity analysis was based on the patients' perceptions of the satisfaction with social support and did not include objective sources of social support (e.g., help to buy medications, access to a support network by the hospital social worker). The same holds true for the assessment of the QLQ-MY symptoms that did not include biochemical disease progression indicators to complement patient's clinical symptoms. It is also important that further research uses convergent and divergent measures that are specific to cancer patients.

\section{6 | CONCLUSION}

The results showed that the Portuguese version of QLQ-MY has appropriate psychometric properties. Thus, this 17 -item version is recommended to assess QoL in Portuguese MM patients. There are several measures to assess QoL in Portuguese cancer's population; however, in this particular type of cancer, the validation with a specific module was needed. The QLQ-MY may also be used to design and monitor interventions in this population focused on the promotion of QoL. 


\section{CONFLICT OF INTEREST}

All authors report no conflicts of interest in this work.

\section{ORCID}

M. Graça Pereira iD https://orcid.org/0000-0001-7987-2562

Gabriela Ferreira iD https://orcid.org/0000-0003-0993-5614

Marta Pereira (iD https://orcid.org/0000-0001-7176-3775

Sara Faria (iD https://orcid.org/0000-0001-9792-5816

Rosário Bacalhau (iD https://orcid.org/0000-0001-5030-5425

Sara Monteiro (iD https://orcid.org/0000-0002-1389-3851

Margarida Vilaça iD https://orcid.org/0000-0002-4349-8633

\section{REFERENCES}

Aaronson, N. K., Ahmedzai, S., Bergman, B., Bullinger, M., Cull, A., Duez, N. J., ... Takeda, F. (1993). The European Organization for research and treatment of cancer QLQ-C30: A quality-of-life instrument for use in international clinical trials in oncology. Journal of the National Cancer Institute, 85, 365-375. https://doi. org/10.1093/jnci/85.5.365

Ålgars, M., Santtila, P., Varjonen, M., Witting, K., Johansson, A., Jern, P., \& Sandnabba, N. K. (2009). The adult body: How age, gender, and body mass index are related to body image. Journal of Aging and Health, 21, 1112-1132. https://doi.org/10.1177/0898264309 348023

American Cancer Society [ACS] (2017). Cancer statistics center: Myeloma. Retrieve from: https://cancerstatisticscenter.cancer.org/?_ ga $=2.189875682 .858032263 .1516614034-723883029.15161$ 21833\#!/cancer-site/Myeloma

Blanchard-Fields, F., Mienaltowski, A., \& Seay, R. B. (2007). Age differences in everyday problem-solving effectiveness: Older adults select more effective strategies for interpersonal problems. The Journals of Gerontology, Series B: Psychological Sciences and Social Sciences, 62(1), P61-P64. https://doi.org/10.1093/geronb/62.1.p61

Boland, E., Eiser, C., Ezaydi, Y., Greenfield, D. M., Ahmedzai, S. H., \& Snowden, J. A. (2013). Living with advanced but stable multiple myeloma: A study of the symptom burden and cumulative effects of disease and intensive (hematopoietic stem cell transplant-based) treatment on health-related quality of life. Journal of Pain and Symptom Management, 46, 671-680. https://doi.org/10.1016/j.jpain symman.2012.11.003

Broers, S., Kaptein, A. A., Cessie, S. L., Fibbe, W., \& Hengeveld, M. W. (2000). Psychological functioning and quality of life following bone marrow transplantation: A 3-year follow-up study. Journal of Psychosomatic Research, 48, 11-21. https://doi.org/10.1016/ S0022-3999(99)00059-8

Cocks, K., Cohen, D., Wisløff, F., Sezer, O., Lee, S., Hippe, E., ... Brown, J. (2007). An international field study of the reliability and validity of a disease specific questionnaire module (the QLQ-MY20) in assessing the quality of life of patients with multiple myeloma. European Journal of Cancer, 43, 1670-1678. https://doi.org/10.1016/j. ejca.2007.04.022

Cohen, J. W. (1988). Statistical power analysis for the behavioral sciences (2nd ed.). Hillsdale, NJ: Lawrence Erlbaum Associates.

Colón, E. A., Callies, A. L., Popkin, M. K., \& McGlave, P. B. (1991). Depressed mood and other variables related to bone marrow transplantation survival in acute leukemia. Psychosomatics, 32, 420-425. https://doi.org/10.1016/S0033-3182(91)72045-8
Cordella, M., \& Poiani, A. (2014). Psychology and cancer. In: M. Cordella, \& A. Poiani (Eds.), Behavioural oncology: Psychological, communicative, and social dimensions (pp. 81-225). New York, NY: Springer. https:// doi.org/10.1007/978-1-4614-9605-2_3

Cronbach, L. J. (1951). Coefficient alpha and the internal structure of tests. Psychometrika, 16, 297-334. https://doi.org/10.1007/BF023 10555

DeVellis, R. F. (2003). Scale development: Theory and applications (2nd ed.). Thousand Oaks, CA: Sage.

Dürner, J., Reinecker, H., \& Csef, H. (2013). Individual quality of life in patients with multiple myeloma. SpringerPlus, 2(1), 397. https://doi. org/10.1186/2193-1801-2-397

Frick, E., Motzke, C., Fischer, N., Busch, R., \& Bumeder, I. (2005). Is perceived social support a predictor of survival for patients undergoing autologous peripheral blood stem cell transplantation? PsychoOncology, 14, 759-770. https://doi.org/10.1002/pon.908

Frick, E., Rieg-Appleson, C., Tyroller, M., \& Bumeder, I. (2006). Social support, affectivity, and quality of life of patients prior to stem cell transplantation and of their support-providers. Journal of Psychosocial Oncology, 23, 15-34. https://doi.org/10.1300/J077v 23n04_02

Fried, L. P., Ferrucci, L., Darer, J., Williamson, J. D., \& Anderson, G. (2004). Untangling the concepts of disability, frailty, and comorbidity: Implications for improved targeting and care. The Journals of Gerontology: Medical Sciences, 59, 255-263. https://doi.org/10.1093/ gerona/59.3.m255

Frodin, U., Borjeson, S., Lyth, J., \& Lotfi, K. (2010). A prospective evaluation of patients' health-related quality of life during auto-SCT: A 3-year follow-up. Bone Marrow Transplantation, 46, 1345-1352. https://doi.org/10.1038/bmt.2010.304

Gozzetti, A., Candi, V., Papini, G., \& Bocchia, M. (2014). Therapeutic advancements in multiple myeloma. Frontiers in Oncology, 4, 241. https://doi.org/10.3389/fonc.2014.00241

Hair, F., Anderson, R., Tatham, R., \& Black, W. (1995). Multivariate data analysis with readings (5th ed.). Englewood Cliffs, NJ: Prentice-Hall.

Hu, L., \& Bentler, P. M. (1995). Evaluating model fit. In R. H. Hoyle (Ed.), Structural equation modeling: Concepts, issues, and applications (pp. 76-99). Thousand Oaks, CA: Sage Publications Inc.

Johnsen, A. T., Tholstrup, D., Petersen, M. A., Pedersen, L., \& Groenvold, M. (2009). Health related quality of life in a nationally representative sample of haematological patients. European Journal of Haematology, 83, 139-148. https://doi. org/10.1111/j.1600-0609.2009.01250.x

Katon, W. J. (2003). Clinical and health services relationships between major depression, depressive symptoms, and general medical illness. Biological Psychiatry, 54, 216-226. https://doi.org/10.1016/ s0006-3223(03)00273-7

Krok, J. L., Baker, T. A., \& McMillan, S. C. (2013). Sexual activity and body image: Examining gender variability and the influence of psychological distress in cancer patients. Journal of Gender Studies, 22, 409422. https://doi.org/10.1080/09589236.2012.708828

Lamers, J., Hartmann, M., Goldschmidt, H., Brechtel, A., Hillengass, J., \& Herzog, W. (2013). Psychosocial support in patients with multiple myeloma at time of diagnosis: Who wants what? Psycho-Oncology, 22, 2313-2320. https://doi.org/10.1002/pon.3284

Lee, S. J., Loberiza, F. R., Antin, J. H., Kirkpatrick, T., Prokop, L., Alyea, E. P., ... Soiffer, R. J. (2005). Routine screening for psychosocial distress following hematopoietic stem cell transplantation. Bone Marrow Transplantation, 35, 77-83. https://doi.org/10.1038/sj.bmt.1704709

Maes, H., \& Delforge, M. (2015). Optimizing quality of life in multiple myeloma patients: Current options, challenges and recommendations. Expert Review of Hematology, 8, 355-366. https://doi. org/10.1586/17474086.2015.1021772

Molassiotis, A., Van den Akkew, O. B. A., \& Boughton, B. J.(1997). Perceived social support, family environment and psychosocial recovery in bone 
marrow transplant long-term survivors. Social Science \& Medicine, 44 317-325. https://doi.org/10.1016/S0277-9536(96)00101-3

Molassiotis, A., Wilson, B., Blair, S., Howe, T., \& Cavet, J. (2011a). Living with multiple myeloma: Experiences of patients and their informal caregivers. Supportive Care in Cancer, 19, 101-111. https://doi. org/10.1007/s00520-009-0793-1

Molassiotis, A., Wilson, B., Blair, S., Howe, T., \& Cavet, J. (2011b). Unmet supportive care needs, psychological well-being and quality of life in patients living with multiple myeloma and their partners. PsychoOncology, 20, 88-97. https://doi.org/10.1002/pon.1710

Mols, F., Oerlemans, S., Vos, A. H., Koster, A., Verelst, S., Sonneveld, P., \& van de Poll-Franse, L. V. (2012). Health-related quality of life and disease-specific complaints among multiple myeloma patients up to $10 \mathrm{yr}$ after diagnosis: Results from a population-based study using the PROFILES registry. European Journal of Haematology, 89, 311-319. https://doi.org/10.1111/j.1600-0609.2012.01831.x

Mortensen, G. L., \& Salomo, M. (2016). Quality of life in patients with multiple myeloma: A qualitative study. Journal of Cancer Science \& Therapy, 8, 289-293. https://doi.org/10.4172/1948-5956.1000430

Mosher, C. E., Redd, W. H., Rini, C. M., Burkhalter, J. E., \& DuHamel, K. N. (2009). Physical, psychological, and social sequelae following hematopoietic stem cell transplantation: A review of the literature. Psychooncology, 18, 113-127. https://doi.org/10.1002/pon.1399

Osborne, T. R., Ramsenthaler, C., de Wolf-Linder, S., Schey, S. A., Siegert, R. J., Edmonds, P. M., \& Higginson, I. J. (2014). Understanding what matters most to people with multiple myeloma: A qualitative study of views on quality of life. BMC Cancer, 14, 1-12. https://doi. org/10.1186/1471-2407-14-496

Pais-Ribeiro, J. L. (1999). Escala de Satisfação com o Suporte Social (ESSS) [Satisfaction with Social Support Scale]. Análise Psicológica, 3(XVII), 547-558. Retrieved from: http://www.scielo.mec.pt/scielo.php?px$\mathrm{ml}: \mathrm{id}=\mathrm{S} 0870-82311999000300010 \&$ script $=$ sci_arttext\&tlng $=\mathrm{pt}$

Pais-Ribeiro, J., Pinto, C., \& Santos, C. (2008). Validation study of the Portuguese version of the QLQ-C30-V.3. Psicologia, Saúde \& Doenças, 9(1), 89-102. Retrieved from: http://www.scielo.mec.pt/ scielo.php?script=sci_abstract\&pxml:id=S1645-008620080001000 08\&lng=en\&nrm=i

Pais-Ribeiro, J., Silva, I., Ferreira, T., Martins, A., Meneses, R., \& Baltar, M. (2007). Validation study of a Portuguese version of the Hospital Anxiety and Depression Scale. Psychology, Health \& Medicine, 12, 225-237. https://doi.org/10.1080/13548500500524088

Potrata, B., Cavet, J., Blair, S., Howe, T., \& Molassiotis, A. (2011). Understanding distress and distressing experiences in patients living with multiple myeloma: An exploratory study. Psycho-Oncology, 20, 127-134. https://doi.org/10.1002/pon.1715

Ramsenthaler, C., Osborne, T. R., Gao, W., Siegert, R. J., Edmonds, P. M., Schey, S. A., \& Higginson, I. J. (2016). The impact of disease-related symptoms and palliative care concerns on health-related quality of life in multiple myeloma: A multi-centre study. BMC Cancer, 16, 1-16. https://doi.org/10.1186/s12885-016-2410-2

Rodrigue, J. R., Pearman, T. P., \& Moreb, J. (1999). Morbidity and mortality following bone marrow transplantation: Predictive utility of preHSCT affective functioning, compliance, and social support stability. International Journal of Behavioral Medicine, 6, 241-254. https://doi. org/10.1207/s15327558ijbm0603_3

Sherman, A. C., Simonton, S., Latif, U., Plante, T. G., \& Anaissie, E. J. (2009). Changes in quality-of-life and psychosocial adjustment among Multiple Myeloma patients treated with high-dose melphalan and autologous stem cell transplantation. Biology of Blood and Marrow Transplantation, 15, 12-20. https://doi.org/10.1016/j. bbmt.2008.09.023
Sherman, A. C., Simonton, S., Latif, U., Spohn, R., \& Tricot, G. (2004). Psychosocial adjustment and quality of life among multiple myeloma patients undergoing evaluation for autologous stem cell transplantation. Bone Marrow Transplantation, 33, 955-962. https://doi. org/10.1038/sj.bmt.1704465

Sloot, S., Boland, J., Snowden, J. A., Ezaydi, Y., Foster, A., Gethin, A., ... Ahmedzai, S. H. (2014). Side effects of analgesia may significantly reduce quality of life in symptomatic multiple myeloma: A cross-sectional prevalence study. Supportive Care in Cancer, 23, 671-678. https ://doi.org/10.1007/s00520-014-2358-1

Smith, A., Howell, D., Patmore, R., Jack, A., \& Roman, E. (2011). Incidence of haematological malignancy by sub-type: A report from the Haematological Malignancy Research Network. British Journal of Cancer, 105, 1684-1692. https://doi.org/10.1038/bjc.2011.450

Stark, D., Kiely, M., Smith, A., Velikova, G., House, A., \& Selby, P. (2002). Anxiety disorders in Cancer patients: Their nature, associations, and relation to quality of life. Journal of Clinical Oncology, 20, 3137-3148. https://doi.org/10.1200/JCO.2002.08.549

Striegel-Moore, R. H., \& Franko, D. L. (2004). Body image issues among girls and women. In T. F. Cash, \& T. Pruzinsky (Eds.), Body image. A handbook of theory, research, and clinical practice (pp. 183-191). New York, NY: Guilford.

Sutherland, H. J., Fyles, G. M., Adams, G., Hao, Y., Lipton, J. H., Minden, M. D., ... Messner, H. A. (1997). Quality of life following bone marrow transplantation: A comparison of patient reports with population norms. Bone Marrow Transplantation, 19, 1129-1136. https://doi. org/10.1038/sj.bmt.1700806

Wedding, U., Honecker, F., Bokemeyer, C., Pientka, L., \& Höffken, K. (2007). Tolerance to chemotherapy in elderly patients with cancer. Cancer Control, 14(1), 44-56. https://doi.org/10.1177/1073274807 01400106

Wells, K. J., Booth-Jones, M., \& Jacobsen, P. B. (2009). Do coping and social support predict depression and anxiety in patients undergoing hematopoietic stem cell transplantation? Journal of Psychosocial Oncology, 27, 297-315. https://doi.org/10.1080/0734733090 2978947

Wenzel, L. B., Donnelly, J. P., Fowler, J. M., Habbal, R., Taylor, T. H., Aziz, N., \& Cella, D. (2002). Resilience, reflection, and residual stress in ovarian cancer survivorship: A gynecologic oncology group study. Psycho-Oncology, 11, 142-153. https://doi.org/10.1002/pon.567

Wilson, I. B., \& Cleary, P. D. (1995). Linking clinical variables with healthrelated quality of life. JAMA, 273(1), 59. https://doi.org/10.1001/ jama.1995.0352025007503

Woertman, L., \& van den Brink, F. (2012). Body image and female sexual functioning and behavior: A review. Journal of Sex Research, 49, 184-211. https://doi.org/10.1080/00224499.2012.658586

Zigmond, A., \& Snaith, R. (1983). The hospital anxiety and depression scale. Acta Psychiatrica Scandinavica, 67, 361-370. https://doi. org/10.1111/j.1600-0447.1983.tb09716.x

How to cite this article: Graça Pereira M, Ferreira G, Pereira M, et al. Validation of the Quality of Life Multiple Myeloma Module Questionnaire (QLQ-MY20) in Portuguese myeloma patients. Eur J Cancer Care. 2019;28:e13128. https://doi. org/10.1111/ecc.13128 